\title{
ОСОБЕННОСТИ ДИНАМИКИ ВОЗВРАЩАЕМОЙ ЧАСТИ ПЕРВОЙ СТУПЕНИ САМОЛЕТНОЙ СХЕМЫ С ТУРБОРЕАКТИВНЫМ ДВИГАТЕЛЕМ
}

Рассмотрены результаты исследований основных динамических свойств возвращаемой части первой ступени самолетной схемы при использовании турбореактивного двигателя на участке ее спасения. Такая компоновка может представлять интерес, поскольку турбореактивные двигатели по сравнению с ракетными имеют значительно меньшие секундные расходы. К тому же их запуск осуществляется в нижних слоях стратосферы или в тропосфере, что избавляет от необходимости размещения на борту запасов окислителя. Такая схема спасения в отличие от альтернативной ракетно-динамической, на наш взгляд, обеспечивает более рациональное использование рабочих запасов топлива, поскольку не требует включения маршевой двигательной установки на участке спасения. Помимо анализа качественной стороны участка спуска такой ступени проводились исследования эффрективности применения крыла с умеренным значением максимального аэродинамического качества и турбореактивного двигателя. В связи с этим рассматривались три варианта возврата ступени. Первый - неуправляемый спуск с нулевым углом атаки в предположении, что ступень является статически устойчивой. Траекторию, полученную при таком варианте спуска, рассматривали как опорную и по отношению к ней оценивали эффрективность использования крыла и турбореактивного двигателя со сравнительно небольшой тягой. Второй и третий расчетные случаи предполагали управляемый планирующий спуск без использования турбореактивного двигателя и с включением последнего в нижней стратосфрере соответственно. Программа угла атаки в двух последних случаях одна и та же. Отдельный интерес представляет возможность обеспечения допустимых значений перегрузок в критических точках траектории спуска и приемлемых значений кинематических параметров в точке касания земной поверхности. В связи с этим программа угла атаки строилась таким образом, чтобы кинематические параметры при касании были по возможности близки к соответствующим значениям для тяжелых самолетов гражданской и (или) военно-транспортной авиации. Моделирование выполнено в среде Microsoft Visual Studio 2010.

Ключевые слова: управляемый спуск, турбореактивный двигатель, кинематические параметры, точка касания, гражданская авиация.

Розглянуто результати досліджень основних динамічних властивостей повертаної частини першого ступеня літакової схеми під час використання турбореактивного двигуна на відрізку їі рятування. Таке компонування може становити інтерес, оскільки турбореактивні двигуни у порівнянні з ракетними мають значно менші секундні витрати. До того ж їх запуск здійснюється в нижніх шарах стратосфери або у тропосфері, що звільняє від необхідності розміщувати на борту запаси окиснювача. Така схема рятування на відміну від альтернативної ракетно-динамічної, на наш погляд, забезпечує раціональніше використання робочих запасів палива, оскільки не потребує увімкнення маршової рушійної установки на відрізку рятування. Крім аналізу якісної сторони відрізка спуску такого ступеня досліджено ефективність застосування крила з помірним значенням максимальної аеродинамічної якості та турбореактивного двигуна. У зв'язку з цим розглянуто три варіанти повернення ступеня. Перший - некерований спуск з нульовим кутом атаки з припущенням, що ступінь є статично стійким. Траєкторію, одержану для такого варіанта спуску, розглянуто як опорну і щодо неї оцінено ефрективність використання крила та турбореактивного двигуна з порівняно невеликою тягою. Другий і третій розрахункові випадки передбачали керований планерувальний спуск без використання турбореактивного двигуна та з увімкненням останнього у нижній стратосфері відповідно. Програма кута атаки у двох останніх випадках однакова. Окремий інтерес становить можливість забезпечувати допустимі значення перевантажень у критичних точках траєкторії спуску та допустимі значення кінематичних параметрів у точці дотику до земної поверхні. У зв'язку з цим програму кута атаки побудовано у такий спосіб, щоб кінематичні параметри під час дотику були по змозі близькими до відповідних значень для важких літаків цивільної і (або) військово-транспортної авіації. Моделювання виконано у середовищі Microsoft Visual Studio 2010.

Ключові слова: керований спуск, турбореактивний двигун, кінематичні параметри, точка дотику, цивільна авіація. 
Basic dynamic properties of the reentry part of the aircraft-type first stage were examined when turbojet engine is used in the recovery phase. Such configuration can be of interest because turbojets have considerably smaller rate of flow in comparison to rocket engines. Moreover, they are launched in the lower stratosphere or in the troposphere so that there is no need to place oxidizer supply on board. This recovery plan differs from an alternative rocket recovery system and, from our point of view, provides more efficient usage of the fuel stores because it doesn't require the main propulsion to be started in the recovery phase. Besides the analysis of qualitative characteristics of the descend phase for this stage, the efficiency of a wing with moderate values of maximum aerodynamic characteristics and a turbojet was studied. In this case three ways for stage recovery were investigated. The first one implied unguided descend with zero angle of attack assuming that the stage is statically stable. This descend trajectory was considered as standard and was used to evaluate the efficiency of the wing and turbojet with relatively small propulsion. The second and the third design cases offered the gliding guided descend with turbojet being started only in the lower stratosphere. The last two cases used the same program for the angle of attack. The possibility to ensure permissible overload values at the critical points of the descend trajectory and acceptable values of kinematic characteristics at the earth surface tangency point are also of great interest. Thereby the program for the angle of attack was developed in a way that allowed kinematic characteristics on touchdown be as close as possible to the corresponding values, shown by civil and/or military-transport heavy aircraft. Simulation was conducted on Microsoft Visual Studio 2010.

Keywords: guided descent, turbojet, kinematic characteristics, tangency point, civil aviation.

\section{Введение}

Общеизвестно, что поиск путей снижения стоимости выведения на орбиту полезного груза в последние годы придал актуальности вопросам разработки многоразовых отделяемых частей первой ступени. Эта задача успешно решена компанией SpaceX на ракете-носителе (PH) Falcon-9. В основу применяемой на Falcon-9 концепции спасения первой ступени положена ракетно-динамическая схема спасения (РДСС) с управляемым входом в атмосферу и вертикальной посадкой [1].

При РДСС происходит несколько включений маршевой двигательной установки (МДУ), что обусловливает соответствующее уменьшение рабочих запасов топлива (РЗТ). В то же время для отделения первой ступени самолетной схемы, бо̀льшая часть участка спасения которой находится в достаточно плотных слоях атмосферы, за счет соответствующей ее компоновки и выбора программы угла атаки можно попытаться избежать включения МДУ на участке спуска, что делает более рациональным использование РЗТ. Для обеспечения безопасных условий приземления на малых высотах возможно применение турбореактивного двигателя (ТРД).

Поэтому изучение общих динамических свойств такой ступени может представлять практический интерес. Ниже отражены основные динамические особенности отделяемой части первой ступени самолетной схемы (ОЧ I) с ТРД, изложена применяв- шаяся методика анализа и проведена оценка возможности получения близких к самолетным посадочных характеристик возвращаемой части такой ступени.

\section{Начальные данные и компоновка ОЧ I с ТРД}

Начальные условия на момент отделения ступени, ее начальный вес и вес топлива для ТРД, принятые при моделировании участка спасения, приведены в окне исходных данных на рис. 1 (текстовые окна в левой верхней части формы). Аэродинамические, центровочные и габаритные характеристики ступени скрыты в исходном коде. Отделение первой ступени происходит вместе с межступенным отсеком весом 500 кгс, сброс которого осуществляется через 2 с после отделения (рис. 2, 3).

Компоновочной схемой исследуемой ступени предусмотрено использование на участке спасения ее ОЧ двигателей АИ-25 ТЛ со степенью повышения давления в компрессоpe $\pi^{*}=9,5$ и общим запасом топлива 1500 кгс. Указанный двигатель с высокой степенью сжатия и высотностью $\sim 11$ км относится к классу ТРД, обеспечивающих длительный полет с дозвуковыми скоростями. Два таких двигателя установлены на учебнотренировочном самолете L-39, а три двигателя АИ-25 (АИ-25 ТЛ является его модификацией) обеспечивают полет пассажирского самолета Як-40 для линий малой и средней протяженности. 
Из сказанного следует, что включение ТРД возможно лишь на заключительном этапе участка спасения. При расчетах учитывался характер зависимости относительной тяги от высоты и скорости полета для двигателей высокой степени сжатия.

\section{Методика анализа и основные резуль-} таты

Рассматривались три способа возврата первой ступени:

a) полет с нулевым углом атаки до момента встречи с земной поверхностью без включения ТРД. Такая траектория спуска ступени практического интереса не представляет и рассматривалась как опорная. Относительно нее проводился анализ эффективности использования крыла и ТРД;

б) управляемый спуск ступени без включения ТРД (в режиме планирования);

в) управляемый спуск с включением ТРД на высотах менее 11 км.

При этом в случаях б) и в) спуск до момента включения ТРД осуществлялся с одной и той же программой угла атаки. Результаты для каждого из трех способов возврата приведены в таблице.

Расчеты участка спасения ОЧ I основаны на используемых в динамике полета уравнениях движения летательного аппарата (ЛА) в вертикальной плоскости с учетом особенностей самолетной схемы. В частности, особенности полета ЛА самолетной схемы учитывались при выборе режима работы ТРД и сравнении значений кинематических параметров ступени в точке касания с их характерными значениями для транспортной авиации. В качестве основных критериев, характеризующих участок возвращения ОЧ I, рассматривались сферическая дальность увода ступени от точки отделения на момент касания и максимальные модули возникающих перегрузок. Учитывались также возникающие в процессе спуска условия входа в плотные слои атмосферы. Поэтому для анализа общих динамических свойств ОЧ I проводились расчеты ее траектории полета при различных программах угла атаки.
C целью обеспечения максимальной дальности увода ступени в плоскости полета первоначально проводилась оптимизация программы угла атаки. Для этого при каждом фиксированном табличном значении числа Маха исследовалась на экстремум функция $\mathrm{k}(\alpha, \mathrm{M})$ зависимости аэродинамического качества от угла атаки и числа М. Из полученных результатов следует, что при входе в плотную атмосферу без включения двигателя и использовании лишь аэродинамических управляющих поверхностей такая оптимизация, как правило, не обеспечивает приемлемых условий спуска с точки зрения значений возникающих при этом перегрузок. Поэтому для обеспечения допустимых значений перегрузок в критических точках волнообразной траектории спуска (рис. 2,3) пришлось отказаться от полета с углом атаки максимального аэродинамического качества.

\section{Качественная картина участка спуска с включением ТРД}

После отделения от РН при указанных на рис. 1 начальных условиях спустя 2 с происходит сброс межступенного отсека (высота 75292,4 м). На 88 с ступень достигает верхней точки траектории на высоте $\mathrm{H}=99126,5$ м (рис. 2), после чего переходит на участок снижения. В начале входа в плотные слои атмосферы на 241 с и высоте 40,6 км ОЧ начинает первый подъем (вторая «волна» на рис. 2).

С этого момента угол наклона траектории к местному горизонту становится положительным и сохраняет свой знак в течение примерно 140 с, за которые ступень проходит через вершину второй «волны».

При переходе на вторую «волну» продольная и нормальная перегрузки резко возрастают и достигают экстремальных за все время спуска значений. Характер изменения перегрузок при управляемом спуске показан на рис. 3. В дальнейшем, совершив несколько быстро затухающих колебаний по высоте (рис. 2), ступень переходит в режим планирования с изменяющимся в диапазоне $\pm 10^{\circ}$ углом наклона траектории. 
Космическая техника. Ракетное вооружение. Space Technology. Missile Armaments. 2018. Bbin. 2 (116)

Три способа возврата первой ступени

\begin{tabular}{|c|c|c|c|}
\hline Наименование параметра & $\begin{array}{l}\text { Неуправляемый } \\
\text { спуск при } \alpha=0^{\circ}\end{array}$ & $\begin{array}{c}\text { Управляемый } \\
\text { спуск без ТРД }\end{array}$ & $\begin{array}{l}\text { Управляемый } \\
\text { спуск с ТРД }\end{array}$ \\
\hline Длительность участка возврата, с & 287 & 1144 & 1179 \\
\hline Сферическая дальность увода, км & 1295,6 & 3926,9 & 3949,6 \\
\hline Широта точки касания, град & 46,4 & 57,76 & 56,8 \\
\hline Долгота точки касания, град & 245,8 & 281,2 & 281,5 \\
\hline $\begin{array}{c}\text { Угол наклона вектора скорости } \\
\text { к горизонту в точке касания, град }\end{array}$ & $-72,2$ & $-10,3$ & $-6,7$ \\
\hline Среднее аэродинамическое качество & 0 & 2,8 & 2,9 \\
\hline $\begin{array}{c}\text { Максимальное значение нормальной } \\
\text { перегрузки (скоростная СК) g }\end{array}$ & 0 & 4,2 & 4,2 \\
\hline $\begin{array}{c}\text { Минимальное значение продольной } \\
\text { перегрузки (скоростная СК) g }\end{array}$ & $-18,9$ & $-2,5$ & $-2,5$ \\
\hline $\begin{array}{c}\text { Максимальное значение } \\
\text { аэродинамического качества }\end{array}$ & 0 & 5,6 & 5,6 \\
\hline Максимальная высота полета, м & 99126 & 99126 & 99126 \\
\hline Число Маха в точке касания & 0,7 & 0,3 & 0,3 \\
\hline Скорость в точке касания, м/с & 253,6 & 105,1 & 105,6 \\
\hline $\begin{array}{c}\text { Продольная скорость } \mathrm{V}_{\mathrm{x}} \text { в точке касания, } \\
\text { м/c }\end{array}$ & 76,1 & 103,5 & 104,9 \\
\hline Вертикальная скорость $\mathrm{V}_{\text {y }}$ в точке касания, & $-241,9$ & $-19,0$ & $-12,5$ \\
\hline
\end{tabular}


Космическая техника. Ракетное вооружение. Space Technology. Missile Armaments. 2018. Bbin. 2 (116)

$\mathrm{M} / \mathrm{C}$

$/ \mathrm{c}$

$\mid$

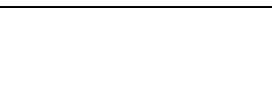

(20. 
(C) 2017 Yuzhnoe Design Office Программный комплекс ПлАСТ

國 Реким расчета

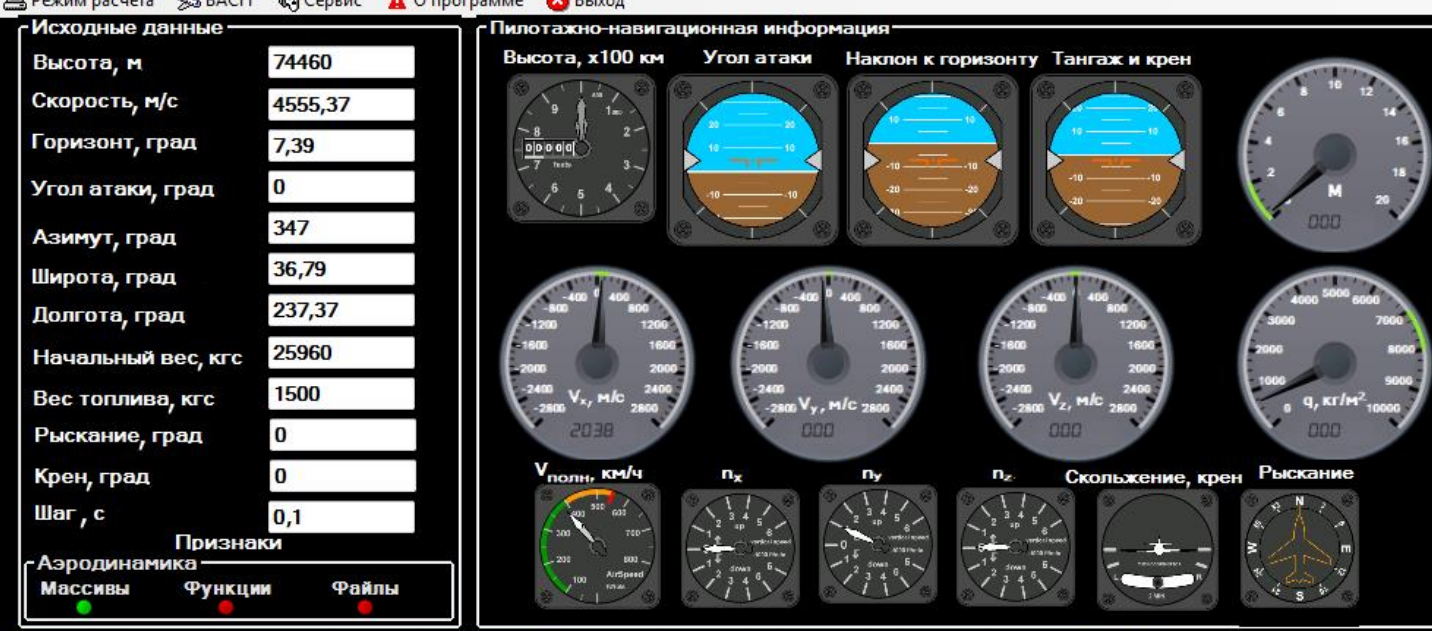

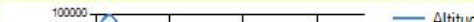
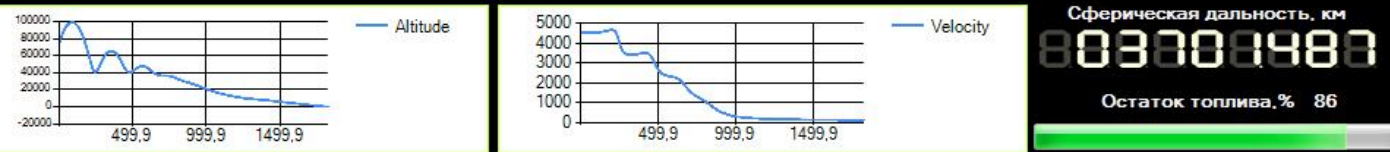

(альностьм M $\quad V_{x}$ M

499.9

Остаток топлива.\% 86

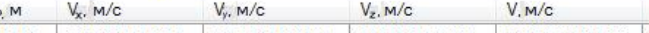

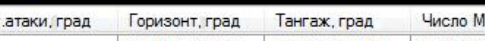

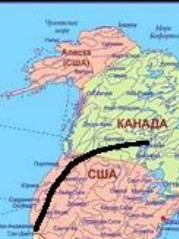

$\begin{array}{lllllllll} & \end{array}$

$\begin{array}{lllll} & \\ 7\end{array}$

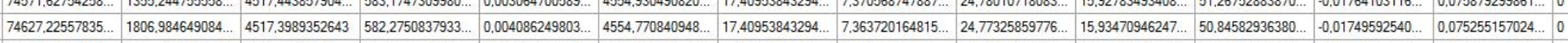

Рис. 1. Исходные данные, пилотажно-навигационная информация в точке касания и результаты расчета на главной форме проекта (Microsoft Visual C++ 2010) 


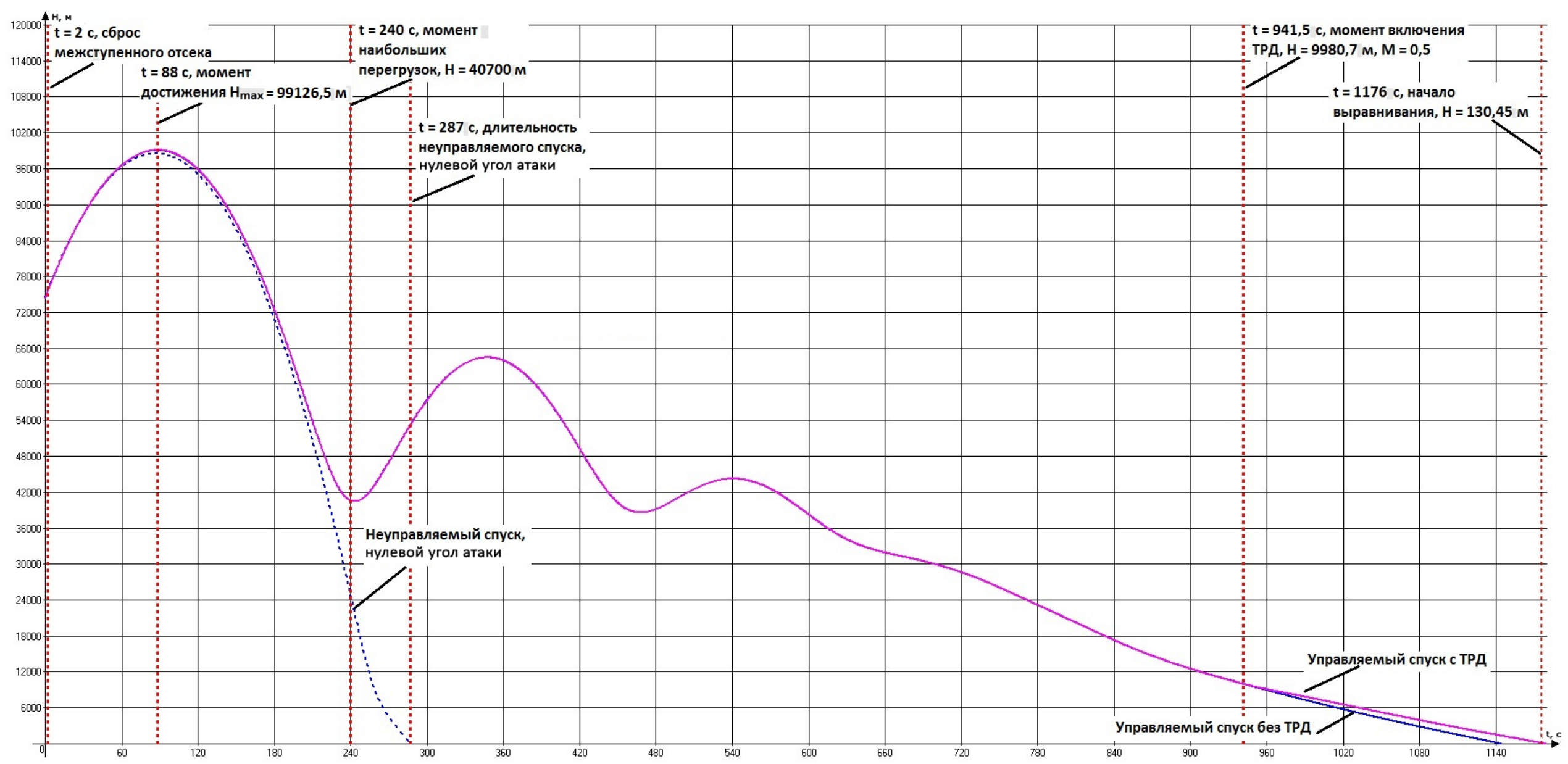

Рис. 2. Зависимость высоты ступени от времени при различных вариантах спуска 
Космическая техника. Ракетное вооружение. Space Technology. Missile Armaments. 2018. Bbın. 2 (116)

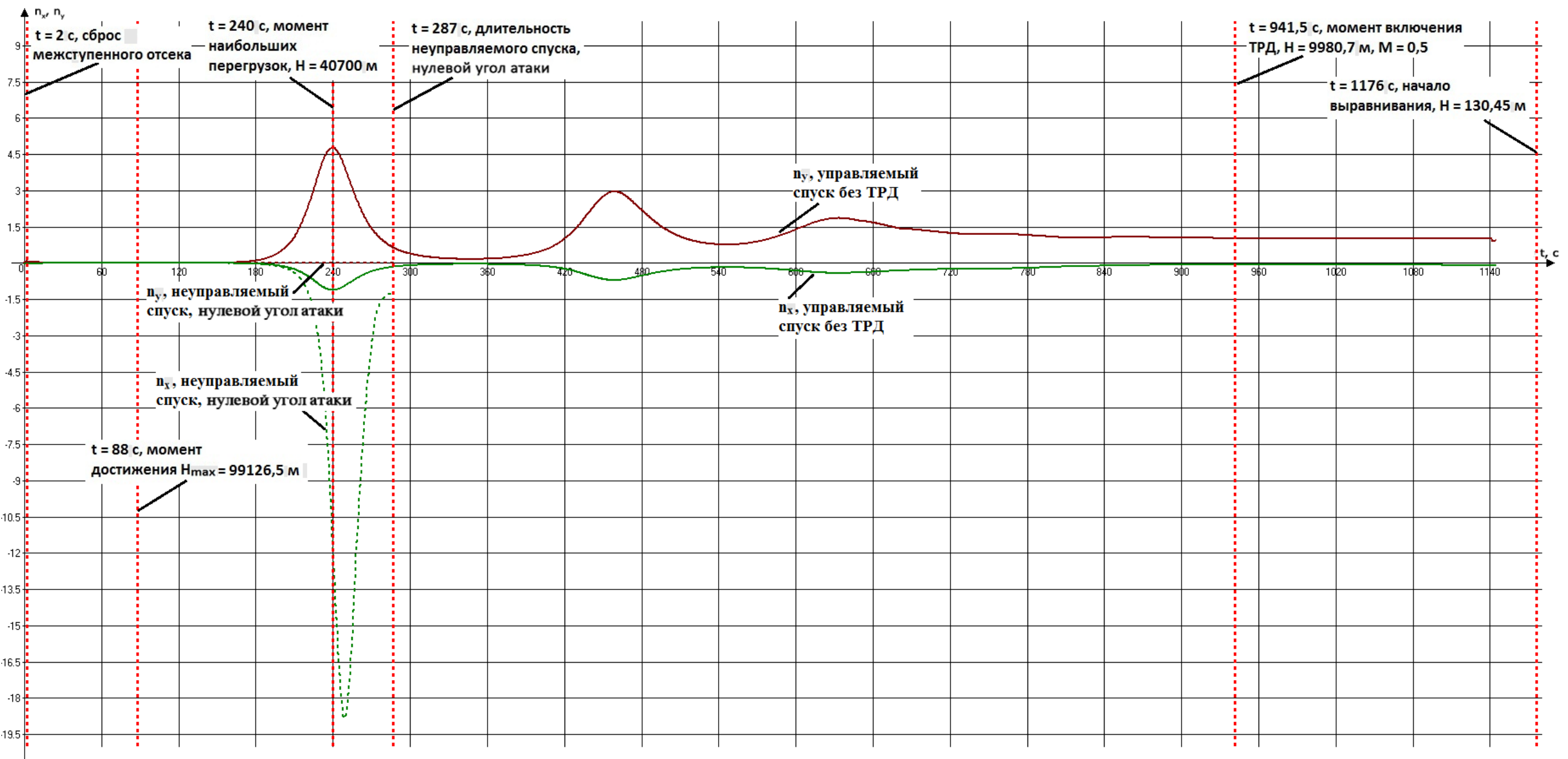

Рис. 3. Значения продольной и нормальной перегрузок на участке спуска (связанная система координат) 
Запуск двигателя на малой высоте после 940 с снижения при соответствующей программе угла атаки обеспечивает дополнительное увеличение дальности увода ступени примерно на 23 км, которые ступень получает возможность пройти примерно за 35 с с включенным ТРД.

Учитывая высотные характеристики двигателя АИ-25 ТЛ, расчет проводился для случая включения ТРД на высотах менее 10 км. Основная часть относительной скорости спасаемой ступени гасится в диапазоне высот от 55 до 30 км при прохождении наиболее критичных по перегрузкам волнообразных участков (рис. 2).

\section{Выводы}

На основании анализа полученных результатов можно сделать следующие выводы о возможности обеспечения условий безопасного приземления:

- при выбранной программе угла атаки на высотах менее 10000 м (высотность ТРД) угол наклона траектории к местному горизонту может достигать $-8^{\circ}$, что несколько выходит за диапазон наиболее часто встречающихся в транспортной авиации значений от -2 до $-6^{\circ}$;

- аэродинамическая компоновка спасаемой ступени при выбранной схеме полета позволяет получить значительную дальность увода с максимальной нормальной перегрузкой порядка $5 \mathrm{~g}$ и продольной 1,5g (рис. 3);

- выбранный режим полета обеспечивает посадочную скорость в точке касания порядка $106 \mathrm{~m} / \mathrm{c}$ (около $380 \mathrm{\kappa м} / \mathrm{ч}$ ) при дальности увода 23700 км. Для сравнения укажем, что минимальные скорости захода на посадку пассажирского самолета Ту-154 в зависимости от его веса лежат в диапазоне 292-332 км/ч.
Несмотря на вполне приемлемую, практически «самолетную», относительную скорость в точке касания, ее вертикальная составляющая при спуске без включения ТРД является несколько завышенной ( 19 м/с). Использование ТРД АИ-25 ТЛ позволяет уменьшить ее до 12,5 м/с за счет выхода на угол атаки максимального качества непосредственно перед касанием. Тем не менее такую посадку следует считать несколько грубоватой, если учесть, что в подразделениях военно-транспортной авиации при десантировании грузов предельная вертикальная скорость у земли ограничена до $12 \mathrm{~m} / \mathrm{c}$. Улучшить условия посадки можно как за счет изменения программы угла атаки, так и за счет использования более мощного двигателя. В целом же использование ТРД АИ-25 ТЛ в рассматриваемом случае можно считать малоэффективным из-за слишком большой удельной нагрузки на его тягу (более 14 кгс на 1 кгс тяги).

\section{Список использованной литературы}

1. Кузнецов Ю. Л., Украинцев Д. С. Анализ влияния схемы полета ступени с ракетно-динамической системой спасения на энергетические характеристики двухступенчатой ракеты-носителя среднего класса // Вестн. Самарского государственного аэрокосмического университета имени акад. С. П. Королева (Национального исследовательского университета). - 2016. Т. 15, № 1. - С. 73-80.

2. Андреевский В. В. Динамика спуска космических аппаратов на Землю. - М.: Наука, 1970. - 230 с.

Статья поступила 16.03.2018 